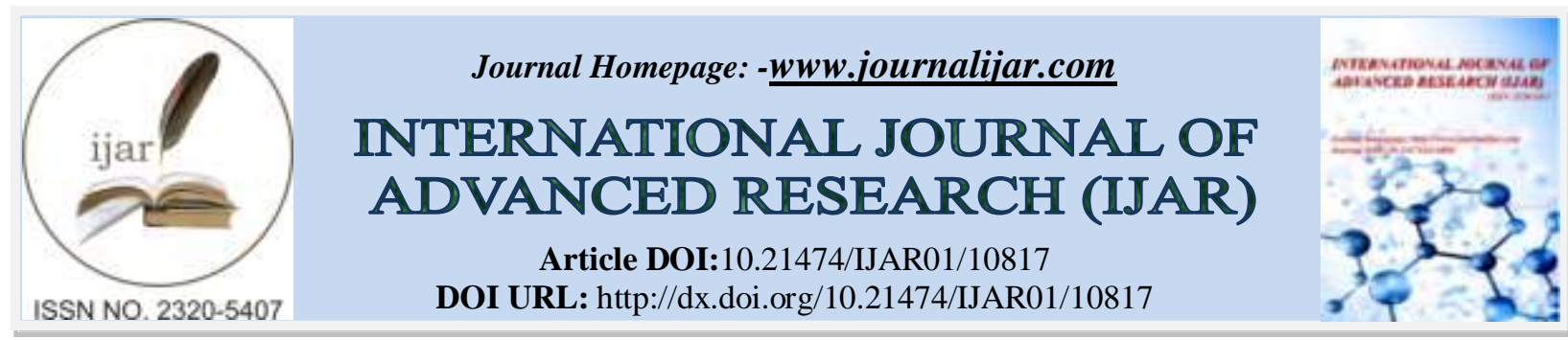

RESEARCH ARTICLE

\title{
PREFERENCES OF VISITING FAST FOOD OUTLETS AND NUTRITIONAL KNOWLEDGE AMONG ADOLESCENTS IN RAWALPINDI CITY
}

Dr. Saba Gulrukh, Dr. Ayesha Babar Kawish and Hina Sharif

Al-Shifa School of Public Health, PIO, Al Shifa Trust Eye Hospital Quaid-e-Azam University, Islamabad, Pakistan.

\section{Manuscript Info}

Manuscript History

Received: 12 February 2020

Final Accepted: 14 March 2020

Published: April 2020

Key words:-

International Fast Food Outlet,

Preferences, Adolescent, Nutrition,

\section{Abstract}

Adolescents make up $21.14 \%$ of Pakistan's population (WHO, 2017). However,the food choices of adolescents are making a vitalpart of theirhealth in the future. With the current increase in fast food consumption, it is necessary to determine the preferences that cause them to select fast food. Determining the level of nutritional knowledge among adolescents. Awareness related to its impact on their health was also an objective of the study.

Objective: This study was designed to measure the various preferences for visiting fast food and general nutritional knowledge of adolescents in international fast food outlets of Rawalpindi city.

Methods: A cross-sectional study was done in Rawalpindi city using a multistage random sampling method to select 330 respondents in the age group of 13 to 19 years selected conveniently. A data tool comprising a self-administered structured questionnaire was applied. The tool gathered Sociodemographic, Preference, and General Nutritional Knowledge data. Chi-square test was applied to determine the associations of the independent variable (Sociodemographic characteristics) with the two dependent variables (Preferences of fast food and General Nutritional Knowledge).

Results: Overall, $66.2 \%$ of adolescents were visiting fast food outlets more than once per week. The primarypreference for visiting fast food outlets in adolescents was entertainment (49.4\%) and convenience (43.9\%). The distance of outlets and working status of parents were also important factors (59.9\% and $60.1 \%$ respectively) their significant $\mathrm{p}$-values were $\mathrm{p}$-value $=0.021$ and $\mathrm{p}$-value $=0.011$ respectively. However, General nutritional knowledge was poor $(-52 \%)$. Financial stability determined by permanent housing and distance were significant with the knowledge their $\mathrm{p}$-values were $(\mathrm{p}$-value $=0.010$ and $\mathrm{p}$-value $=0.000$ respectively)

Conclusion: The study concluded that preferences behind fast food eating are entertainment and convenience which is linked with the working status of parents and outlet distance while those have permanent houses and again a close distance of outlets is

\section{Corresponding Author:- Dr. Saba Gulrukh}

Address:- Al-Shifa School of Public Health, PIO, Al Shifa Trust Eye Hospital Quaid-e-Azam University, Islamabad, Pakistan. 
linked with knowledge.It seems like financial stability can lead to better education and hence can be one of the factors of better overall general nutritional knowledge. However, there is no relationship between preferences and nutritional knowledge.

Copy Right, IJAR, 2020,. All rights reserved.

\section{Introduction:-}

Preferences of visiting fast food outlets and nutritional knowledge among adolescentsin Rawalpindi city

Adolescence is a complex phase of an individual's life, which is characterized by rapid changes in the body's physical attributes, changes in behaviour and attitudes, increase in knowledge and skills. Hormonal and neurodevelopmental changes, development of coping skills with social and emotional changes (WHO, 2017). At this stage, some of the long-lasting connections between health and riskybehaviours are established. While knowledge and environment also create habits. Incautious eating habits during adolescence can be related to mental health. (WHO, 2017). Nutritional knowledge is another important aspect of developing healthy eating behaviours. During the adolescent period, individuals are usually naïve to the long-term consequences of a poor-quality diet, and lack of nutritional knowledge helps reinforce this risk-takingbehaviour or, worse, it can create false perceptions about the quality of food they may be consuming as being better and healthy. Therefore, nutritional knowledge becomes extremely valuable in building good eating habits and negating harmful ones. (Suneeta, 2014). In recent times with the adoption of busy and fast lifestyles, eating 'fast food' has become a prevalent trend, especially in adolescents. For example, as per the National Center for Health Statistics 2011-2012 report, in the United States of America, $34.3 \%$ of adolescents were consuming fast food on an everyday basis (Bases, 2015). In a survey of 2016, 45\% of Canadians ate fast food less than once per week, $38 \%$ one to three times only, and $8 \%$ do not consume fast food at all. In China, 19.9\%, India 34\%. According to a 2013 national survey, in Pakistan, $42 \%$ of females and $33 \%$ of males consume fast food (Ali, 2014). These statistics show that this is not only a global issue, but the problem is penetrating in Pakistan too.As per the latest studies,the fast-food sector will expand annually at $20 \%$ in Pakistan (Akhtar, 2013).

Simple actions have complicated consequences.Therefore, if this growing issue is not understood and managed earlier, this will lead to compromise the community's health. Over recent years, the concept of international fastfood chains has gained rapid adoption in urban communities. These chains have introduced fast-food restaurants or outlets whereby customers are not only able to order and buy fast food but also use the facilities to socialize while they eat their meals. The glamourous marketing techniques and the posh and modern facilities that these restaurants offer have gained much popularity. High volume music, colourful environment, comfortable seating, and courteous staff all add to the appeal of these outlets.

\section{Methodology:-}

This study was quantitative research;a cross-sectional design was used to achieve the objectives of this study.The study duration to complete this current research was six months from January 2018 to June 2019, after the approval of synopsis. However,the study population was male, female adolescents of age group 13 to 19 years, who were visiting international fast food outlets of Rawalpindi city. The sample selection was based on the inclusion and exclusion criteria.It was carried out in standalone fast food outlets of international chains in Rawalpindi city of Pakistan (Figure 1). These international outlets have their private building premises and parking areas. They provide different variety of fast food and fizzy drinks while they have a play area and party halls too. Fast food dine-in and take away outlets. The sample size was estimated by using open Epi, Version 3; it is an open-source calculator software. Previous literature showed a 28\% prevalence (Yahya, Zafar \& Shafiq, 2013). Based on a 95\% confidence limit, $5 \%$ precision, non-response allowance of 5\%, and a population size of one million. These are standard settings in the open-source calculator. Based on the calculations, the sample sizefor this study was determined to be 310 and rounded up to 330 .

$\mathrm{N}=\mathrm{Z} 2 \mathrm{p}(1-\mathrm{p}) / \mathrm{e} 2$ IfN $=1.962(0.28)(1-0.28) / 0.052=310$

In this study, those male and female individuals are included who come in the age group from 13 to 19 years.Moreover, visiting fast food outlets once per week. Only international fast food outlets of Rawalpindicity were included. Those individuals who had any mental disability, not completed the questionnaire or are not willing to fill 
the questionnaire. Local fast-food brands were also excluded.This study has no sampling frame because the study was performed in an international fast food outlet.

In the current study, Multistage random sampling was used to collect samples from the population. This study was conducted in three stages, in stage one Rawalpindi city area was divided into peri-urban and urban areas, this division was based on road declared for commercialization within the jurisdiction of RDA (Rawalpindi Development Authority, 2015). Then from these two peri-urban and urban areas, with the urban population of 4,003,664 residents of Rawalpindi city (Pakistan Bureau of Statistics, 2017), applying the national ratio of 0.55 outlets per 100,000 residents (Memon, 2016), we estimated approximately twenty-two international outlets. Then we obtained the list of international fast-food franchise outlets operating in Pakistan (U.S.Government, 2018); from that list, five international chains were selected, which falls in the operational definition of this study. For further confirmation, we geolocated these outlets from Google Maps ${ }^{\circledR}$. The selection resulted in identifying fifteen outlets belonging to these international fast-food chains. All the outlets were in specified urban clusters of Sadder, Chaklala and Bahria Phases 4, 7 and 8 (Rawalpindi Development Authority, 2007).

In stage two, through simple random lottery method, three international outlets out of fifteen were selected, usinga folded piece of paper outlets name and area was written from there three pieces of folded paper was selected not by researcher itself. Then in stage three through convenience sampling method hundred and ten samples were selected from each outlet with no gender division to achieve a total of 330 sample sizes of this research. The map in Figure 1depicts these locations.

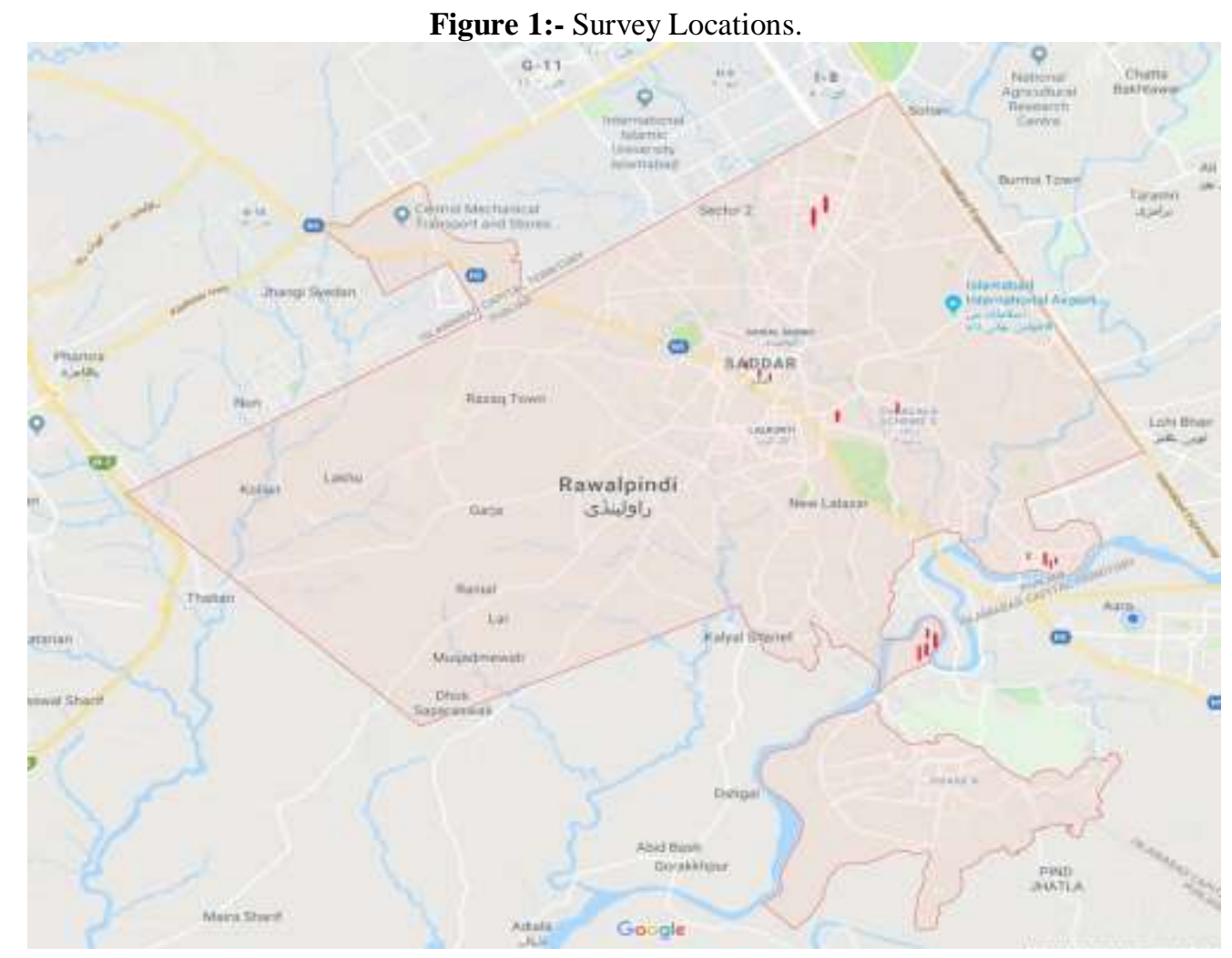

\section{Data Collection tool}

Data collection was performed from a self-administered structured questionnaire. A questionnaire was produced based on previous studies to get data on sociodemographic variables, preferences of visiting fast food outlets, basic nutritional knowledge status. This questionnaire was designed with the questionnaires used in previous studies for the sociodemographic and performance section.(Majabadi,2016). Nutritional knowledge status was based on (Alsaffar A, 2012), and the questionnaire was designed on principles of (Wardel et al., 1999) tool, which was modified according to this study by the researcher and used in this study. Simple questions are introduced with no jargon and in understandable English, which was validated after pilot testing. The answer options were mutually 
exclusive. Reliability of two scales preferences and nutritional knowledge status all questions were assessed through Cronbach's Alpha was 0.6 for 39 variables. Then subsections of preference and nutritional knowledge were assessed through the inter-item correlation test. The value of the test was 0.1 .

The questionnaire was based on three major sections. First, section A contains sociodemographic characteristics. Section B (preferences) (Majabadi, 2016) includes a total of twelve questions. These questions are based on subsections of preferences, two questions for habitual, and then four were for convenience, two for socialization, two for entertainment while two for the taste of fast food. In section C, twelve questions were asked to assess the basic nutritional knowledge of adolescents based on four variables.

The primary outcome comes out to be an assessment of preferences (habitual, convenience, socialization, entertainment, taste ) while basic nutritional knowledge status ( Dietary recommendations, Meal Proportion, Source of Nutrients, Choosing everyday food).A pilot study on $10 \%$ of the sample population was done before data collection.

\section{Actual data collection}

To get permission from international outlets of fast food administration, a formal letter, which includedthe purpose of the study, was issued by the Al-Shifa Eye Trust before pilot testing and formal data collection. Written consent was obtainedafter an oral explanation. Consent form was established in two parts; the first part was about the purpose of the survey, no harm, confidentiality, and no incentives were given at the time of questionnaire filling to participants then the second part was the certificate that the respondent is satisfied from the procedure of per questionnaire filling (WHO, 2018) attached at the Annex B. Firstly, researcher briefly introduced herself. The confidentiality of the respondent was contained byprovidingI.D.The questionnaire was self-administered. However, the researcher was present and explained to respondents and be there at the time of need. The filled questionnaire was inspected and assessed for any missing and unclear data every day. Data collection took place in approximately one and a half months. All filled forms were kept in plastic bags, and no one had allowed assessing them other than the researcher.

\section{Data analysis procedure}

Data was transformed;the outcome variable was computed and later categorized in two categories with the help of the median (Table 1). For section B, cut off point was taken as the median of each sub-section below that was low preferences and above that cut off was high. While for section $\mathrm{C}$, the total knowledge median was taken as cut off point; below it was poor and above it was good and, in this way, computed into a new binary variable.

Table 1:- Median of all preferences variables.

\begin{tabular}{|l|l|l|l|l|l|l|}
\hline & Habitual & Convenience & Socialization & Entertainment & Taste & $\begin{array}{l}\text { Nutritional } \\
\text { knowledge }\end{array}$ \\
\hline Median & 2.00 & 5.00 & 3.00 & 3.00 & 3.00 & 22.0 \\
\hline
\end{tabular}

Descriptive statistics were calculated for sociodemographic characteristics, preference, and knowledge variables. Data was used to summarize in the form of percentages and frequencies. Percentage tables and charts as bar and pie charts were used to report Results.

Inferential Statistics was calculated fromthe Chi-square test of independence. It was applied to determine the statistical association between independent and outcome variables, while the association between outcome variables were also checked. Asymptomatic P-Value of less than or equal to 0.05 was statistically significant.

\section{Results:-}

A total of 330 respondents were included in the study. Out of 330 respondents [160 (48.5\%)] were male while [169 $(51.2 \%)]$ were females. These males and females were categorized into three categories, 13-14 years [28 (8.5\%)], $15-16$ years [60 (18.2\%)], most subjects were in 17-19 years [240 (72.7\%)] category. However, most of the respondents [166 (50.6\%)] were spending PKR 1500 to PKR 2000 every week in fast food eating, which is the least amount of spending among these categories. While 2000 to 3000 Rs. group were spending [95 (29.0\%)] and 3000 Rs. and more category [60 (18.3\%)] while others were [7 (2.1\%)].There is a very high rate of a visit to fast food outlets, with at least $66.2 \%$, are visiting more than once a week,Figure 2. 
Figure 2:- Socio Demographic variable characteristics.

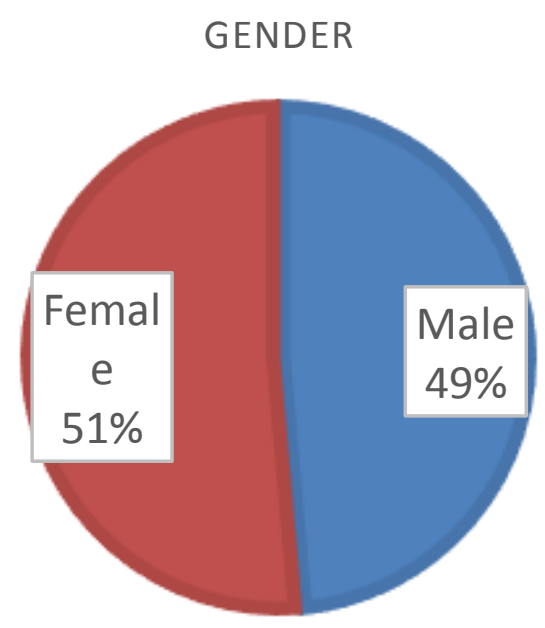

AGE GROUP

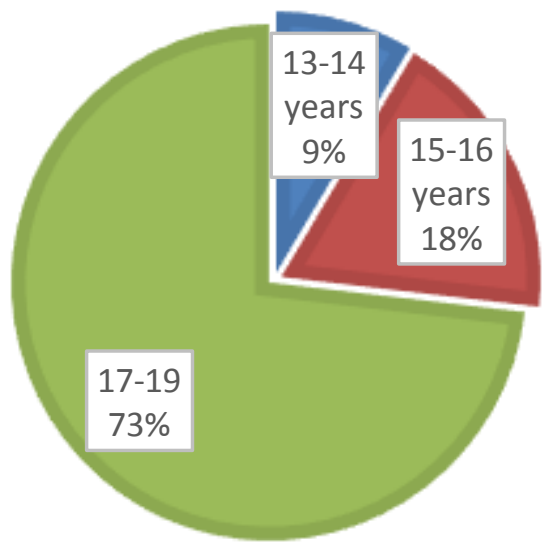

FAST FOOD SPEND/WEEK PKR.

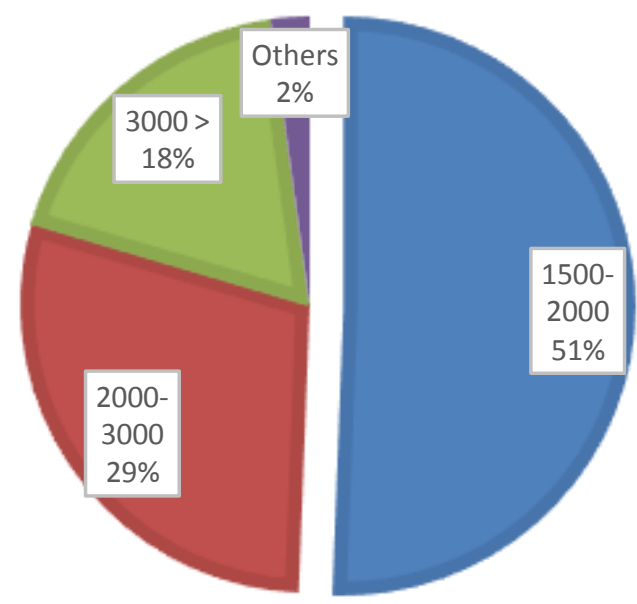

FREQUENCY OF VISITING FAST

FOOD OUTLETS PER WEEK

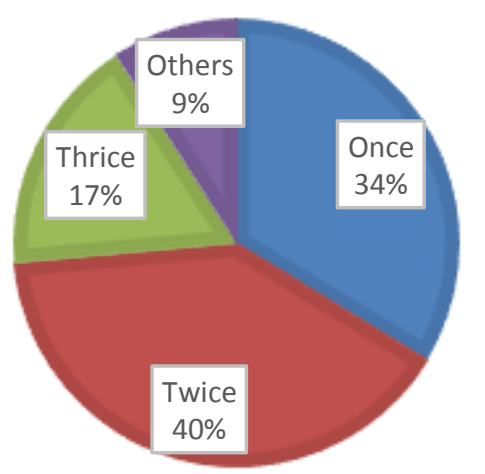

\section{Outcome variable:Preferences}

The outcome variable(preferences) was of five components or subsections, which were as follows, Habitual, Convenience, Socialization, Entertainment, and Taste.

We standardized by taking cut off point for every component of the outcome variable (preferences). Above that cut off point comes in the category of users represented as 'yes' and below were represented as 'no.' At the same time, the evaluation of habitual component among adolescents who eat fast food, we served this purpose by asking questions with numerous options, for example, the question, "how often do you go to eat fast food in a week?", was evaluated through four options: once, twice, thrice every day. Out of 330 respondents, $64.2 \%(\mathrm{~N}=212)$ were not habitual while, $35.8 \%(\mathrm{~N}=118)$ wereinclined towards fast food outlet visiting. The entertainment component of the outcome variable (preferences) was $49.4 \%(\mathrm{~N}=163)$, showed the highest percentage among all components. The convenience element of the outcome variable (preferences) was $43.9 \%(\mathrm{~N}=145)$, which was the second most crucial component amongst adolescents who were visiting fast food outlets.

Furthermore, the Taste component was assessed through a comparison question. $33.6 \%(\mathrm{~N}=111)$ respondents liked the taste of fast food. This component was evaluated through questions like 'do you enjoy the taste of fast food more than the taste of homemade meals?', through three different options, 'yes' had the highest score, 'no' was second and 'least' was do not know. However, taste and habitual component percentages were close to each other. 
Socialization had very less impact, 1.5\% ( $\mathrm{N}=5)$, amongst the subject population.The percentages of these components of preferences are shown below in Figure 3.

Figure 3:- Percentage of the outcome variable (Preferences).

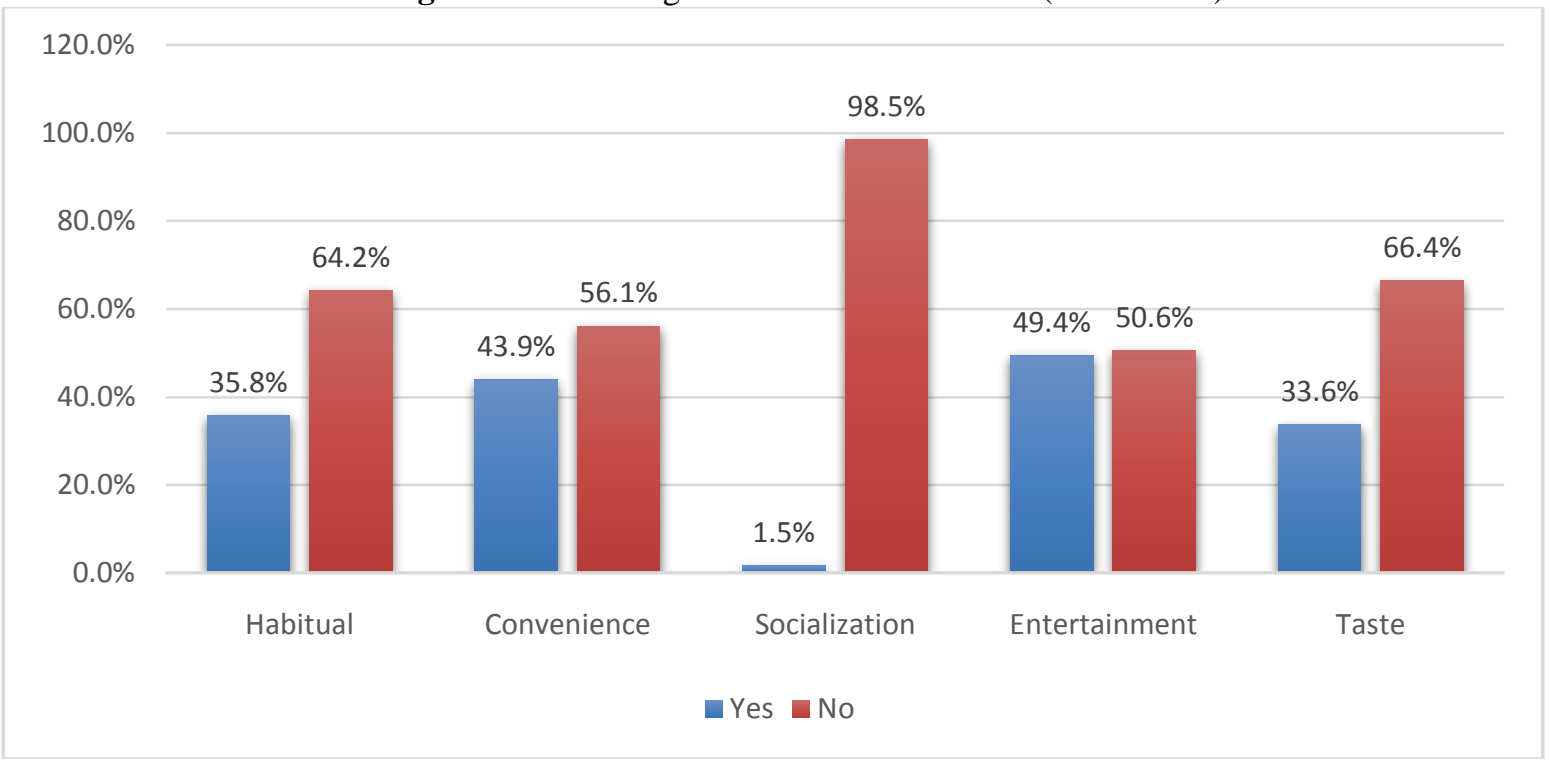

\section{Outcome variable: Nutritional Knowledge}

Out of total respondents, male and female-only $48.2 \%(\mathrm{n}=159)$ had good nutritional knowledge. While $51.8 \%(\mathrm{n}=$ 171) had showed poor nutritional knowledge. There is very little difference between poor and good nutritional knowledge status, as in Figure 4.

Figure 4:- Level of nutritional knowledge amongst adolescent.

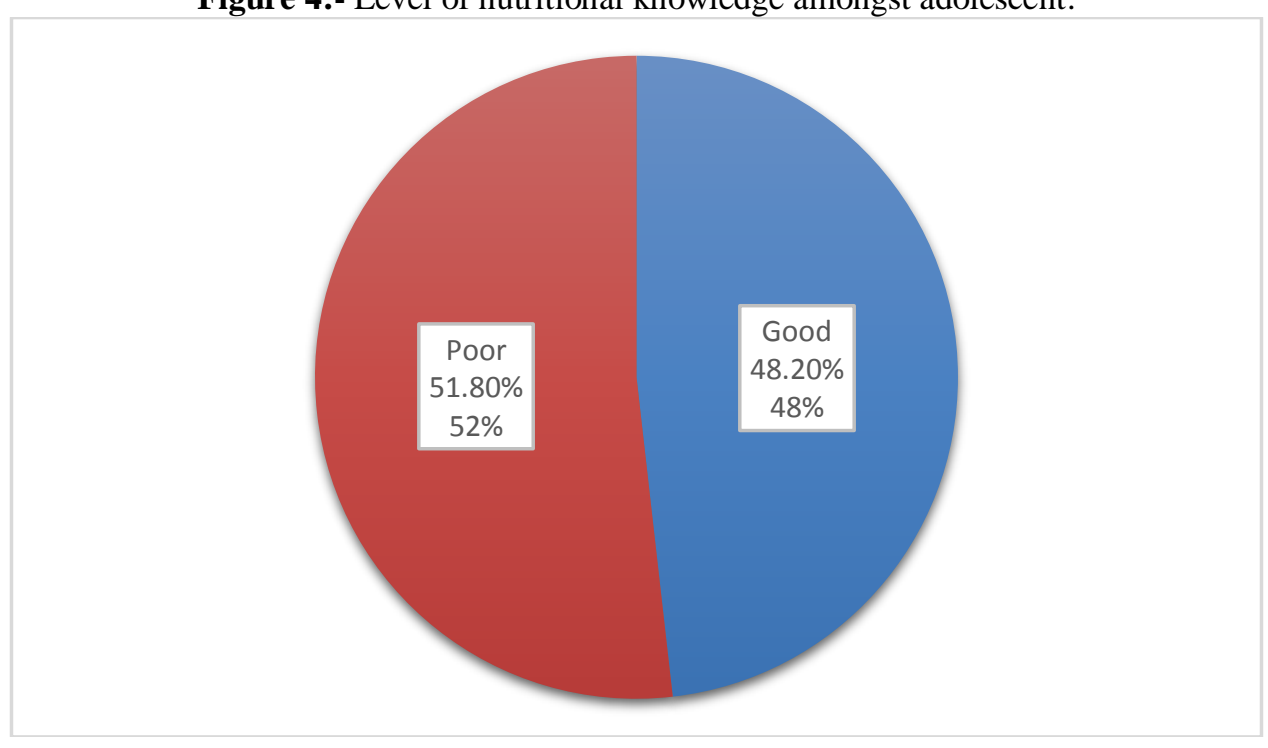

The overwhelming majority of respondents, $258(78.2 \%)$, had poor knowledge of the word nutrients, with only $45(13.6 \%)$ and $27(8.6 \%)$ having good or fair understanding, respectively.

Results showed that health issues due to excess sugar had the highest count, 55.3\%. The knowledge of common disease-causing factors like fats, sugars and other such ordinary dietary inputs is given inFigure 5 below. 
Figure 5:- Knowledge about general disease-causing factors.

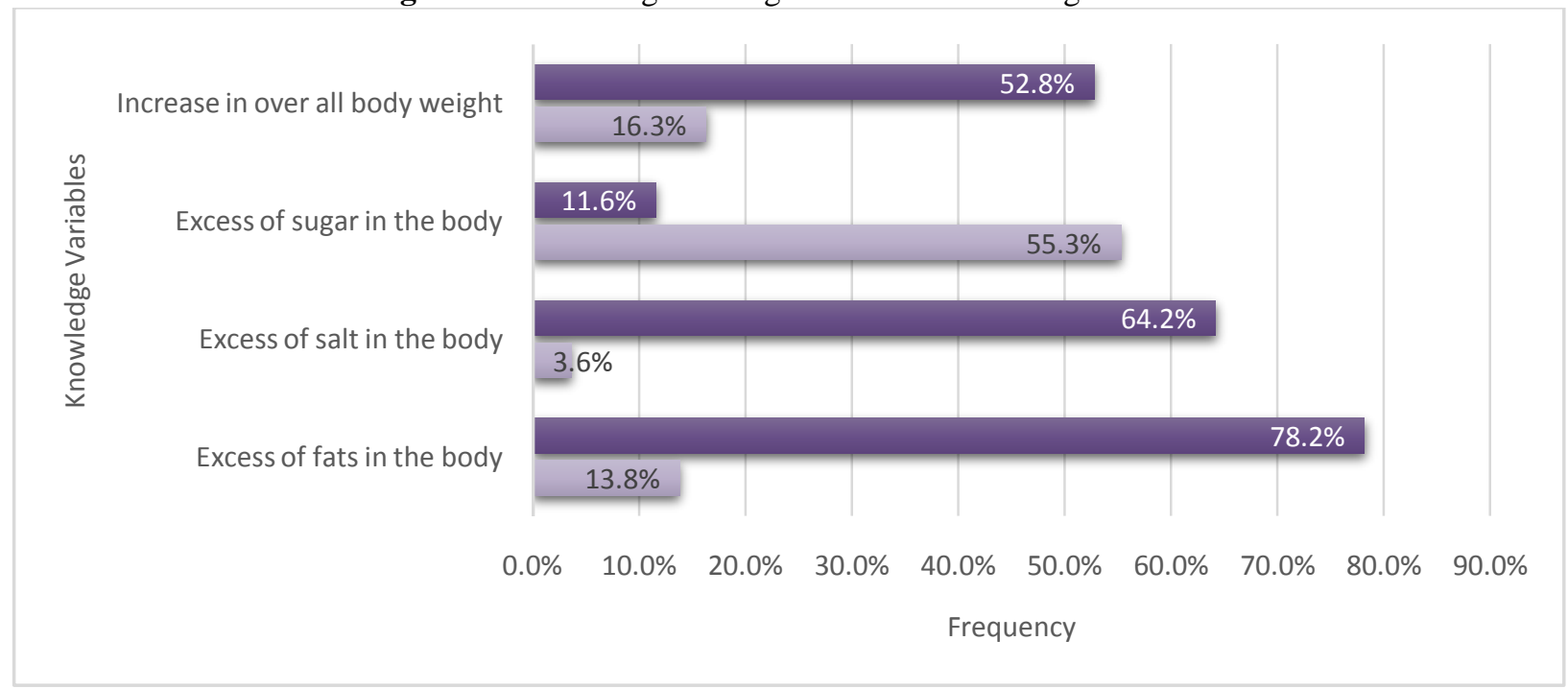

There is a very high rate of visits to fast food outlets, with at least $66.2 \%$, are visiting more than once a week,Figure 6.below

Figure 6:- Frequency of weekly visits to a fast food outlet.

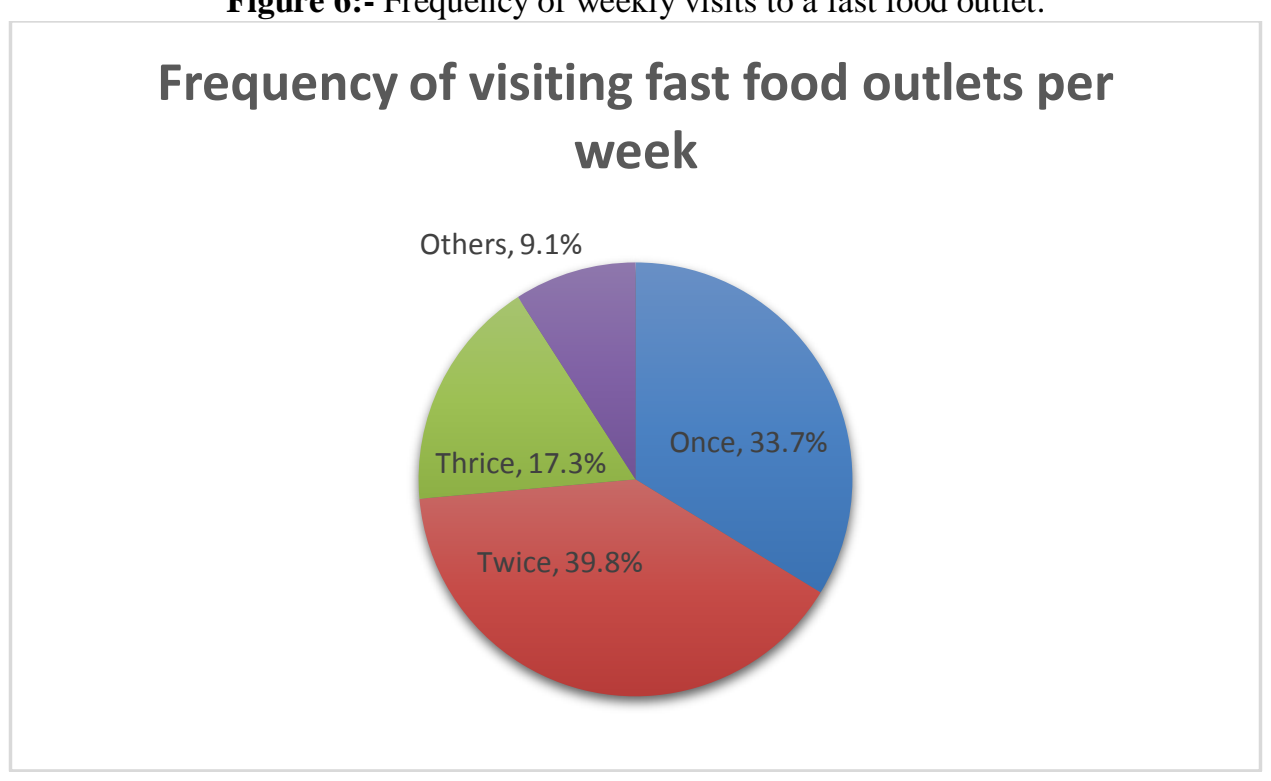

Test results reported that parents who were working as they were single or both working, their association with preferences was statistically significant. However, working fathers were [86(42.0\%)] prefer more fast food than working mothers[33(82.5\%)]. Another significant association was reported for distance from the resident place to fast food outlets.

Chi-square test results showed statisticalsignificance for those adolescents whose families havea permanent house in Rawalpindi city. They were $53.6 \%(\mathrm{n}=11), \mathrm{p}$-value $=0.010$ and significant with distance $\mathrm{p}$ - value $=0.000$.

\section{Discussion:-}

This study was conducted to determine why adolescents prefer fast food? Furthermore, whether they know about nutrition or not. Furthermore, Preferences of fast food have any relationship with general nutritional knowledge. The 
highest percentage, which came out through the current study, was entertainment (49.4\%) and convenience (44\%). Habitual $(35.8 \%)$ and taste $(33.6 \%)$ respectively are uniform. However, socialization $(1.5 \%)$ was calculated as the least persistent reason. These findings are almost consistent with the study in the USA in 2008, where respondents feel fast food is the least frequent way of socialization (33\%) fast food is quick $(92 \%)$ and convenient $(80 \%)$ (Rydell et al., 2008). Current trends around fast-food eating are similar in Rawalpindi city, as were in the USA back in 2008 (Rydell et al., 2008). The study revealed that $66.2 \%$ of adolescents visit fast food outlets more than once per week. This situation is alarming, andit could be their obsessiveness of fast food, which can be further explored.

The overall nutritional knowledge of this study is $48.2 \%$ good, and $51.8 \%$ is poor. Despite having a slight difference, they still prefer fast food due to inadequate knowledge and other factors like based on this study results due to a closer distance of residence $\mathrm{p}=.000$ from a fast food outlet. Theiraccess to fast food outlets becomesmore convenient as compared to those that lived further away; however, permanent house $p=0.010$ one of the factors of financial stability determined that $53.6 \%$ are more users of fast food. Another reason for preferring fast food from the current study is that mostly $54.1 \%$ of adolescents choose whatever is available, and they are unconcerned about the nutritional value of their meals.

The basic understanding of what is nutrient is $78.2 \%$ poor, while $13.6 \%$ is good. A similar question was asked in the Pakistan National Survey in 2011 generally showedlowknowledge levels about nutrients (Government of Pakistan and UNICEF, 2011).Micronutrient deficiencies are a significant problem in Pakistan; however, $36.2 \%$ from this study have complete ideas and knowledge about Iron deficiency, while 51.4\% do not know about this health issue. In this study, 36.0\% know Vitamin A, and the previous survey back in 2011 showed that $24 \%$ of mothers had an idea about Vitamin A.(Government of Pakistan and UNICEF,2011). Similarly, in the case of Vitamin B deficiency, according to this study, only $45.1 \%$ understand this issue, and the previous study showed $34.4 \%$ (Government of Pakistan and UNICEF, 2011).The current study showed the highest, 55.3\%, knowledge of health issues due to an excess of sugar were reported. Clearly, this shows the prevalent myths that diabetes occurs due to high sugar intake (Anderson, 1991).

\section{Strengths and limitations:}

The strength of this study is the development of a locally contextualized questionnaire, including various measures of sociodemographic, preferences, and knowledge aspects, after modifying from the previous literature review (Majabadi, 2016). One of the biggest strengths of this specific study is that data was collected from fast food outlets for the first time. Another plus point of this data collection from outlets is the removal of recall bias from the study by collecting data directly from outlets. The researcher ensured complete response if any missing data was left out after rechecking it was fulfilled by $10 \%$ new responses. This study emphasizes some of the aspects, for example, understanding of nutrients and its deficiencies.

The limitation of this study was that it was a cross-sectional study, so the cause and effect relationship cannot be established between sociodemographic characteristics with preferences and nutritional knowledge. This study can be further explored through qualitative analysis for various factors, like, behaviours. This analysis was not performed due to time and resource constraints.

Conflict of interest: the author declared no conflict of interest.

\section{Conclusion:-}

The phenomena of increasing fast food eating in adolescents from Rawalpindi city are due to entertainment and convenience mainly. Their nutritional knowledge level, as revealed through this study, comes out to be poor. Even those adolescents who have better knowledge levels are not applying it when eating fast food. Their knowledge about the main macro and micronutrients is deficient.Therefore, after almost a decade, knowledge about micronutrient deficiencies has still not shown much further improvement.This lack of knowledge can be addressed by focused andaggressive steps in community health education since the fast food industry is proliferating rapidly.

\section{References:-}

1. WHO | nutrition. (2017). WHO. Retrieved from https://www.who.int/topics/nutrition/en/

2. Bases, D. (2015). Over a third of U.S. children and adolescents eat fast food daily - Reuters. Retrieved June 22, 2019, from https://www.reuters.com/article/us-usa-fastfood-calories/over-a-third-of-u-s-children-andadolescents-eat-fast-food-daily-idUSKCNORG2S820150916 
3. Ali, S. (2014). Fast Food consumption in Pakistan - Brandsynario. Retrieved June 22, 2019, from https://www.brandsynario.com/fast-food-consumption-in-pakistan/

4. Akhtar, M. (2013). Fast Food Industry of Pakistan Growth and History. Retrieved June 23, 2019, from https://ilm.com.pk/pakistan/pakistan-information/fast-food-industry-of-pakistan-growth-and-history/

5. Saleem Kanwal. (n.d.). Global food chains dominating Pakistan's fast food industry - PAGE Blog. Retrieved from http://blog.pakistaneconomist.com/2018/01/22/global-food-chains-dominating-pakistans-fast-foodindustry/

6. Pakistan Bureau of Statistics. (2017). Block Wise Provisional Summary Results of 6th Population \&amp; Housing Census-2017. Retrieved from http://www.pbs.gov.pk/sites/default/files/bwpsr/punjab/RAWALPINDI_SUMMARY.pdf

7. Yahya, F., Zafar, R., \& Shafiq, S. (2013). Trend of Fast Food Consumption and its Effect on Pakistani Society. Food Science and Quality Management, 6088(January 2013), 1-8. Retrieved from www.iiste.org

8. Memon, N. A. (2016). Fast Food: I2nd largest industry in Pakistan. Food Journal Pakistan, (July-August). Retrieved from http://www.foodjournal.pk/2016/July-August-2016/PDF-July-August-2016/Exclusive-articleDr-Noor-Fast-Food.pdf

9. U.S. government. (2018). Pakistan - Franchising | export.gov. Retrieved June 2, 2019, from https://www.export.gov/article?id=Pakistan-Franchising-best-prospect

10. Alsaffar, A. A. (2012). Validation of a general nutrition knowledge questionnaire in a Turkish student sample. Public Health Nutrition, 15(11), 2074-2085. https://doi.org/10.1017/S1368980011003594

11. WHO. (2018). HEALTH SITUATION. Retrieved from http://apps. who.int/gho/data/node.cco

12. Rydell, S. A., Harnack, L. J., Oakes, J. M., Story, M., Jeffery, R. W., \& French, S. A. (2008). Why Eat at FastFood Restaurants: Reported Reasons among Frequent Consumers. Journal of the American Dietetic Association, 108(12), 2066-2070. https://doi.org/10.1016/j.jada.2008.09.008

13. Askari Majabadi, H., Solhi, M., Montazeri, A., Shojaeizadeh, D., Nejat, S., Khalajabadi Farahani, F., \&Djazayeri, A. (2016). Factors Influencing Fast-Food Consumption Among Adolescents in Tehran: A Qualitative Study. Iranian Red Crescent Medical Journal, 18(3), e23890. https://doi.org/10.5812/ircmj.23890

14. UNICEF. (2011). The State of the World's Children 2011. Retrieved from https://www.unicef.org/adolescence/files/SOWC_2011_Main_Report_EN_02092011.pdf

15. Anderson, G. H. (1991). Facts and myths about sugar. Boletin de La Asociacion Medica de Puerto Rico, 83(9), 408-410. Retrieved fromhttp://www.ncbi.nlm.nih.gov/pubmed/1807277

16. Government of Pakistan \& UNICEF Pakistan. (2011). National Nutrition Survey Pakistan 2011. Aga Khan University, Pakistan Medical Research Council (PMRC) Nutrition Wing, Cabinet Division, Government of Pakistan and UNICEF Pakistan, 1-104. Retrieved from https://www.humanitarianresponse.info/system/files/documents/files/59_National Nutrition Survey-2011.pdf. 